\title{
Beyond the stage-damage function: Estimating the economic damage on residential buildings from storm surges
}

\author{
Lea Skraep Svenningsen ${ }^{1}$, Lisa Bay ${ }^{1}$, Mads Lykke Doemgaard ${ }^{1}$, Kirsten Halsnaes ${ }^{1}$, Per \\ Skougaard Kaspersen ${ }^{1}$, and Morten Dahl Larsen ${ }^{1}$ \\ ${ }^{1}$ Climate Risks and Economics, DTU Management, Technical University of Denmark, 2800 Kongens Lyngby, Denmark \\ Correspondence: Lea Skræp Svenningsen (leasks@dtu.dk)
}

\begin{abstract}
Given the predicted global increase in extreme weather events, such as storm surges, the design of effective response strategies requires a very detailed and accurate understanding of the major factors driving damage costs. The costs of climate hazards are usually estimated using engineering approaches, which, based on different levels of building-specific information, link water inundation levels to the costs incurred by building owners. More recently, a number of scientific papers have pointed

5 to the limitations of such approaches because they omit important information about key context-specific factors such as emergency response options and a range of social factors reflecting age and social networks in the affected communities. This study contributes to this growing literature by providing rigorous and detailed econometric estimates of damage costs for residential buildings resulting from a storm surge that impacted large parts of Denmark in December 2013. We collected a comprehensive data set consisting of insurance cost data, the characteristics of individual buildings (size, age, construction materials, heating source and distance from bodies of water), emergency services, previous experience with storm surges in the municipality and socio-economic factors. Our results indicate that the isolated effect of inundation depth on damage costs is highly sensitive to the inclusion of other explanatory variables. In our models the isolated effect of inundation depth is more than halved when our full set of control variables is included. Furthermore, our findings highlight the importance of controlling for spatial effects, such as the level of emergency services and socio-economic conditions. Discussing the transferability of our findings, we highlight key sensitivities when using our damage functions in other contexts.
\end{abstract}

Keywords: Damage cost function, Storm surges, Climate adaptation, OLS regression, Flooding, Insurance data

\section{Introduction}

The damage costs of pluvial and fluvial flooding are usually estimated using engineering approaches, which typically focus on buildings and link water inundation levels to refurbishment costs. The simple approach using a relationship between inundation depths and resulting damage costs alone (often referred to as the stage-damage function) forms the core basis of a vast number of studies and relates to direct damage alone (Smith, 1994; Middelmann-Fernandes, 2010). The damage cost functions in these models are often simple, and other key elements beyond building structure and refurbishment costs have not been considered, despite their importance in assessing damage cost levels. In this paper, we develop an extended cost model of building damage 
from coastal flooding based on very detailed insurance damage cost data from a storm surge that occurred on 5 December 2013. This event caused severe damage in northwest Europe, including Denmark. Basing damage costs on insurance data has its own merits and limitations. Insurance payments are revealed data and as such provide an accurate, often third-party estimate of the damage costs, but they only capture one damage category, such as building and contents damage. However, insurance schemes vary with respect to whether compensation covers the full price of refurbishing buildings, whether the age of a building is reflected in the loss value and specific rules of self-payment if the same building has been repeatedly flooded. Accordingly, insurance data on damage costs can be difficult to compare across different periods and regions. Insurance cost data have been applied in multiple studies of both coastal flooding and pluvial and fluvial flooding (e.g. André et al. (2013); Jonkman et al. (2008); Zhou et al. (2013)). Damage cost estimates can also be collected using survey methods. This approach has the advantage that it can include more damage categories than are generally covered by insurance payments, but it suffers from limitations such as personal reports being inaccurate due to limited memory or different understandings of what should be included in specific cost categories. The choice of either method might also reflect aims, insured damage costs being of interest to insurance companies, total damage costs to governments (local and national) and academics (Jongman et al., 2012).

To expand the simple stage-damage function, we combine the damage cost data based on insurance payments with house characteristics, flood characteristics, socio-economic variables, the emergency response and experiences of flooding. Our contribution to the literature is in line with several studies that have sought to refine the classic stage-damage function by introducing more influential parameters and/or variables into the calculations, but it concludes that their approach to estimating damage cost functions still includes a lot of uncertainties. On the geophysical side, the additional factors often included in the literature are flood duration, velocity, sediments and contamination, whereas the physical nature of houses (e.g. building materials) and national or regional economies affect the variations in costs, and therefore geographical transferability, at a certain inundation depth (Merz et al., 2010). The warning and forecast aspects and the experience and role of the community and one's neighbours may also be important, as Grahn and Nyberg (2014)), for example, have pointed out. As a result of these additional influential factors, the stage-damage function is characterized by a certain degree of scatter around the best-fit correlation. This has been addressed as a severe challenge to studies of damage cost assessments by, for example, Smith (1994); Merz et al. (2014); Prettenthaler et al. (2010); Moel et al. (2012); Prahl et al. (2018); Amadio et al. (2019).

Specifically, Carisi et al. (2018)highlight a significant increase in the predicted extent of flooding when a multivariate approach is used rather than using inundation depth alone, while at the same time highlighting the need for proper data. In their study, building area and water velocity were found to be as important as maximum inundation depth. Along these lines, Schröter et al. (2014) found that additional explanatory variables other than inundation depth improve the performance when transferred to other settings both temporally and spatially. However, having used several damage-function models drawn from the literature, they also emphasize that the overall structure of the model is a controlling factor in its performance.Jongman et al. (2012) also employ several damage-function models taken from the literature and conclude that, other than the choice of model, regional adjustments reflecting local economic conditions might be an important aspect requiring incorporation into further and larger-scale studies. Ootegem et al. (2015) find improvements in predicting damage by introducing additional explanatory variables, among them non-hazard indicators related to building characteristics, behavior and socio-economic factors. 
These inclusions and the consideration of additional explanatory variables have also highlighted the need to consider intangible variables such as adaptive capacity and preparedness (Merz et al., 2004), as important determinants of the damage costs.

Overall, the previous findings in the literature highlight the importance of including several explanatory variables when estimating the economic damage costs from flooding, herein inundation depth, building construction materials, flood characteristics and the adaptive capacity of the affected population. Furthermore, previous studies also highlight the sensitive nature of damage cost estimates, discussing how transferable damage estimates are between storms, geography and over time (Cammerer et al., 2013; Merz et al., 2014), highlighting the need to account for model uncertainty (Figueiredo et al., 2017) ${ }^{1}$.

These studies are carried out especially within the fields of pluvial and fluvial flooding (e.g. Ootegem et al. (2015); Spekkers et al. (2014); Merz et al. (2004, 2010); Amadio et al. (2019); Pistrika et al. (2014); Jongman et al. (2012)). ). In this paper, the focus is on flooding from storm surges (coastal flooding), an area where the existing literature is scarce. Flooding from storm surges has different characteristics from pluvial and fluvial flooding in that, for example, the water is saltwater, potentially causing different types of damage. Transferring damage models estimated from pluvial flooding to coastal flooding might therefore provide incorrect expected economic damage costs.

To study the importance of geography or the spatial effect on damage costs, in our dataset we have collected storm damage costs from 29 different municipalities in Denmark that were affected by the same storm. This allows us to study how the same storm can give rise to different damage costs across municipalities by controlling for differences in, for example, emergency responses and socio-economic factors. Spatial effects have increasingly been recognized in both theoretical and applied econometric work (Anselin and Arribas-Bel, 2013; Kelejian and Prucha, 2010), but also specifically in relation to damage costs from flood events (Cammerer et al., 2013).

The novelty of this study lies in both its combination of different data sources and the variables it includes in the development of a multivariable econometric model that estimates the expected damage costs from storm surge-induced coastal flooding. By coupling influencing variables from a comprehensive set of sources and sectors, including new insurance data, national emergency management data, flood simulations and building characteristics, we are able to control rigorously for a great number of parameters. In the literature all these have previously been identified separately as important determinants of damage costs but, to the best of our knowledge, have never been analyzed within the same econometric framework.

\section{Materials and methods}

To perform our econometric estimate of damage costs, we rely on several different sources of data, which are presented in the subsections below. The specification of the econometric models is given in Section 2.2.

\subsection{Data}

In this study, we combine variables from six unique datasets. Table 1 presents each of the included variables, their units and levels, and their dataset source. The following sections present each dataset individually.

\footnotetext{
${ }^{1}$ Some recent papers have investigated and compared the performance of individual models and model ensembles, see Figueiredo et al. (2017, 2018)
} 
https://doi.org/10.5194/nhess-2020-30

Preprint. Discussion started: 16 March 2020

(c) Author(s) 2020. CC BY 4.0 License.

(c) (i)

Table 1. Description of variables in the final data set

\begin{tabular}{|c|c|c|c|}
\hline Variable & Unit and range & Source & Spatial level \\
\hline \multicolumn{4}{|l|}{ Building damage } \\
\hline Damage cost & $€: 0.18-497.12$ thousand Euro & Danish Storm Council & Building \\
\hline \multicolumn{4}{|l|}{ Storm surge characteristics } \\
\hline Return Period & Years: $7-1000 \mathrm{yr}$ & Flood modelling; Flood water statistics & Building \\
\hline Depth & Cm: $1-296 \mathrm{~cm}$ & Flood modelling & Building \\
\hline \multicolumn{4}{|l|}{ Building characteristics } \\
\hline Size & $m^{2}: 45-364 m^{2}$ & BBR & Building \\
\hline Rooms & Number: $2-9$ rooms & BBR & Building \\
\hline Age & Years in 2016: 0-239yr & BBR & Building \\
\hline Floor & Number (only groundfloor incl.) & BBR & Building \\
\hline Building type & Dummy according to type & BBR & Building \\
\hline Heating source & Dummy according to type & BBR & Building \\
\hline Outer construction & Dummy according to type & BBR & Building \\
\hline Renovations & Years since last: 0-91 years & BBR & Building \\
\hline Distance to lake & Meter: $22.5-1566.2 \mathrm{~m}$ & Tokes data(?) & Building \\
\hline Distance to coast & Meter: $3.4-2817.7 \mathrm{~m}$ & Tokes data(?) & Building \\
\hline Distance to habour & Meter: 3.4-7997.0m & Tokes data(?) & Building \\
\hline \multicolumn{4}{|l|}{ Flood experience } \\
\hline Previous storms & Number of insurance claims: 0-602 & Danish Storm Council & Municipality \\
\hline Previous storms cost & Index $100=$ highest expenditures & Danish Storm Council & Municipality \\
\hline \multicolumn{4}{|c|}{ Emergency Management Agency Services, EMAS } \\
\hline EMAS duration & Hours: $0-582 \mathrm{hr}$ & Danish EMAS & Municipality \\
\hline EMAS count & Number of services: $0-38$ & Danish EMAS & Municipality \\
\hline \multicolumn{4}{|l|}{ Social vulnerability indicators } \\
\hline Retired persons & Percentage: $19-35 \%$ & Statistics Denmark & Municipality \\
\hline Income per capita & $€: 37-80$ thousand Euro & Statistics Denmark & Municipality \\
\hline Expenditure on medical consultantions & $€:$ 292-404 Euro/capita & Statistics Denmark & Municipality \\
\hline
\end{tabular}

Note: The reference year for the damage cost from the Danish Storm Council is in current prices through the period 2013-2017. The reference year for income per capita and expenditure on medical consultations is 2019. Reference categories for dummy variables in subsequent econometric models are: Heating source $=$ district heating and Outer construction $=$ wood 


\subsubsection{Building damage}

From the Danish Storm Council (DSC), we obtain realized insurance claims at the household level. The DSC (DSC, 2019), is an independent council that falls under the Danish Ministry for Business and Growth. The DSC decides whether an official storm surge has occurred, since insurance claims can only be made under these circumstances. The DSC then handles all insurance claims and compensation related to the event. Compensation is only granted if the water level has a recurrence interval of at least twenty years. The DSC covers the majority of all damage to building structure and chattels, with a few exceptions such as terraces, separate garages and carports, and moveable property stored in basements and rooms below ground that are not approved for living ${ }^{2}$. The DSC also grants compensation for the costs of cleaning and rehousing. The data cover the period since 2013, when all claims were collected at the address level and were divided into residential, leisure (summer cottages) and business. The dataset does not contain any information on the inundation depth causing the damage. The storm surge of 2013 resulted in nation-wide economic losses, with insurance payouts for residential building owners in 29 out of 97 Danish municipalities. 2,761 individual insurance claims were made, of which 2,136 received payouts from the DSC, amounting to a total of approximately $130 \mathrm{~m} €$. In developing the econometric model we only use data for building damage to residential buildings, for which we have 551 unique observations covering a third $(45 \mathrm{~m} €)$ of the total insurance payouts (1). The full descriptive statistics from the DSC are available listed from in Table A1 in the Appendix.

\subsubsection{Storm surge characteristics}

One of the main factors influencing the shape and size of the damage cost function is the inundation depth (Amadio et al., 2019). Because the DSC data do not contain this information on a household basis, inundation depths are estimated by simulating flooding during the storm surge using a simple static 2D surface flood model framework. A high-resolution digital elevation model (DEM) is combined with data from a network of water-level measuring stations indicating the maximum water level at sea and the corresponding return period during the storm surge (DCA, 2018). The outputs of the flood model are flood hazard maps showing the maximum extent and depth of flooding for the different geographical areas. To obtain inundation depths, the nearest measuring station for each of the DSC-registered insurance claims was found, and flood simulations were conducted, raising the sea level to match the observed maximum water level for each observation. Only areas that are directly connected to the sea are considered as having been flooded during the storm surge. The DEM has a pixel size of $0.4 \mathrm{~m}$ but is aggregated to a $10 \mathrm{~m}$ resolution for operational simulation times. Furthermore, all protective infrastructure such as floodgates and sluices are closed during the flood simulations, as would be the case during a storm surge. To quantify the performance of our flood-model simulation, we evaluated accuracies for stand-alone residential buildings by spatially comparing the DSC data (insurance claims) with the flood hazard maps. We selected a hot-spot area near Roskilde Fjord for evaluation, as this represents a large share of the insurance payouts, see Figure 1. A three-step procedure was used for the evaluation. First, we assigned each of the stand-alone buildings to the closest water-level measuring station (three stations are located in this area).

\footnotetext{
${ }^{2}$ For a complete list of losses not covered by the DSC (in Danish): Stormrådets Dækningsvejledning, 28. juni 2018. A simplified list in English: https://www.danishstormcouncil.dk/artikler/danishstormcouncil/storm-surge/how-to-receive-compensation-after-a-storm-surge/
} 


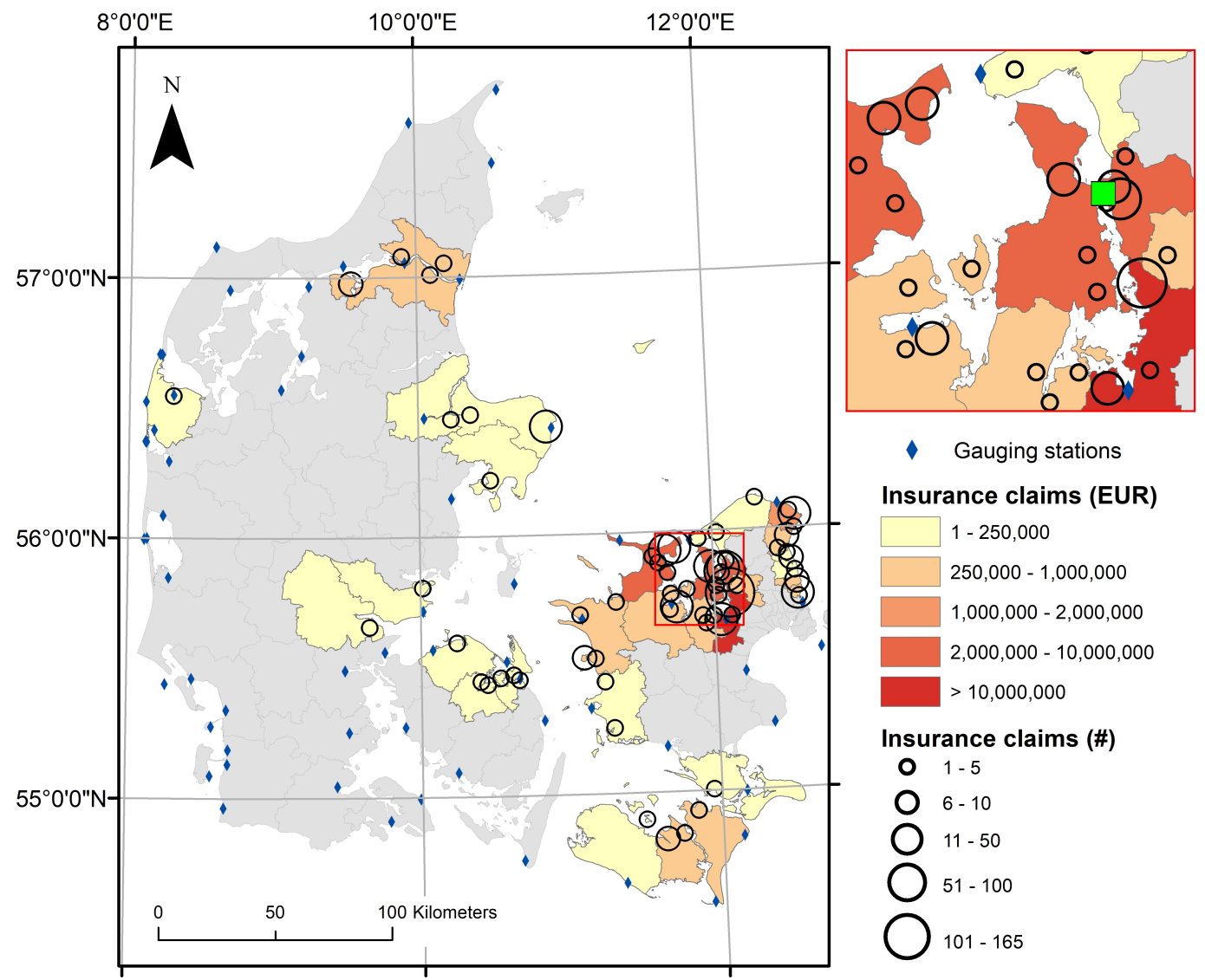

Figure 1. Insurance claims for residential buildings in Denmark following the storm surge of 5 December 2013. The green square in the top right section marks the hot-spot, analysed in Figure 2. The GIS layer for the Danish administrative regions is open-source and obtained through: https://sdfe.dk/hent-data/danmarks-administrative-geografiske-inddeling, @SDFE

Secondly, we conducted three individual flood simulations, one for each subset of buildings linked to a specific measuring station. Finally, we evaluated the number of accurately and inaccurately flooded buildings by means of an overlay analysis of the flood-hazard maps and the DSC data, assuming that the latter represent the "ground truth".

Figure 2 gives the results of the model evaluation when simulating storm surge "Bodil" for Frederikssund municipality in the eastern part of Roskilde Fjord, Denmark, which suffered large-scale economic damage during the storm surge. The flood model captures 67 of the 70 buildings with DSC insurance claims, but over-estimates the total flooded area, as 38 buildings without insurance claims are flooded in the model. However, we do not know whether these buildings actually experienced high water levels during the storm surge, but were better protected and therefore did not experience any economic losses. However, a general concern in using static flood models is that the flooded area may be over-estimated, as the model does not consider the 


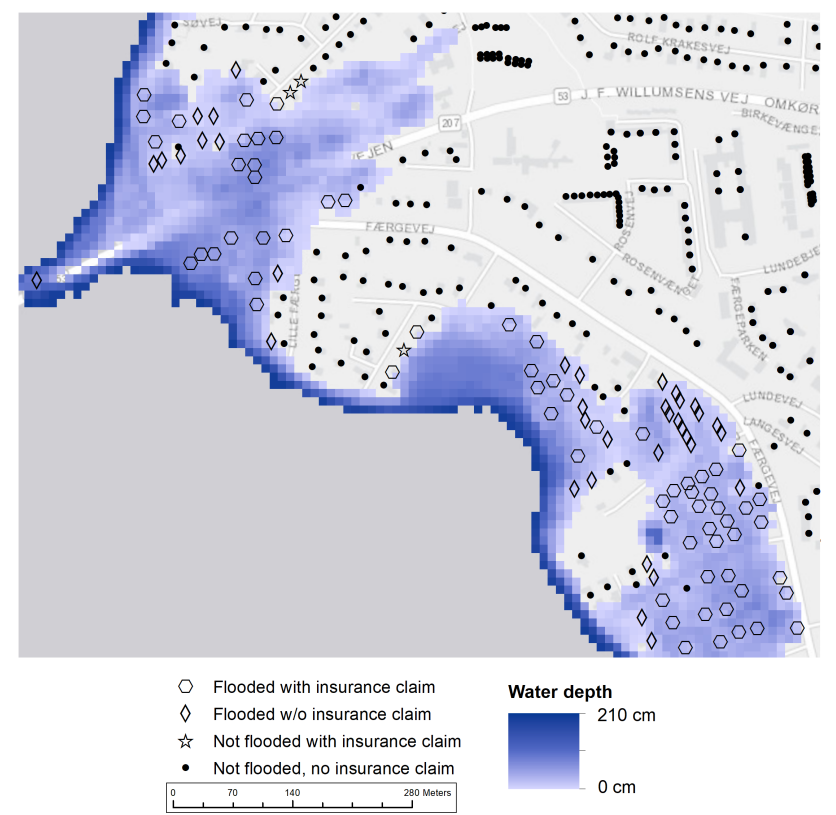

Figure 2. Results of flood model evaluation for Frederikssund municipality. The GIS layer for the Danish coastal line is open-source and obtained through: https://sdfe.dk/hent-data/danmarks-administrative-geografiske-inddeling, CSDFE

duration of the storm surge and thus envisages low-lying, inland areas being flooded that the water might not reach. In addition, the model does not account for the natural infiltration and filling of drainage systems, which contribute to the over-estimates.

\subsubsection{Buildling characteristics}

The Danish Building and Housing Register (BBR) contains information on building and housing characteristics for all developed properties in Denmark. The register contains a large variety of variables for each building, such as type, year of construction, number of rooms, size, garage and garden size, as well as technical details like building materials and heating type (BBR, 2019).

\subsubsection{Flood experience}

As an indicator of the experience of flooding, we use insurance data from the DSC for previous storm surges from 1999-2008 aggregated at the municipality level. As shown in Table 1, the two indicators are i) the number of insurance claims and ii) an index number of the total compensation sum with index 100 corresponding to approximately $10,700,000 €$, which corresponds to the highest claim within a municipality in that period ${ }^{3}$. In order to capture the relative differences in the previous size of

\footnotetext{
${ }^{3}$ The compensation sum cannot be compared with the 2013 sum, as the legislation was changed due the scale of the damage from the storm surge, resulting in a vast increase in the compensation.
} 
insurance claims between municipalities, we use an index instead of the actual insurance claim. In estimating our model to account for multicollinearity, only the number of insurance claims is used.

\subsubsection{Emergency Management Agency Services, EMAS}

AA dataset consisting of all emergency and rescue services involved in the storm surge for the period 4-12 December 2013 was retrieved with the permission of the Danish Emergency Management Agency (DEMA, 2019). The dataset covers emergency and rescue services relating to both strong winds, high water levels and inundation. To isolate the effect of the emergency services for storm-surge issues, data related to strong wind damage was removed (e.g. roofs blown off, trees falling on roads inland). The services include pumping out water, installing water tubes, providing sandbags and personal rescues. For every action, the data provide information on the time spent on the service and the number of persons involved in it. However, the data on the number of staff involved in a given action are estimates based on the time spent and the number of cars sent. Due to uncertainties in these estimates, we only include time spent on a given action in the dataset. The data are on the address level. However, since the emergency services' activities will often benefit larger areas, the data points have been summarized for each Danish municipality. Data on emergency and rescue services therefore relate to the municipal level.

\subsubsection{Social vulnerability indicators}

Socio-economic data were retrieved from the Statistics Denmark database, StatBank (StatisticsDenmark, 2019). Data on income per capita, public expenditure on medical consultations and retired population in 2013 were retrieved for all 98 municipalities in Denmark. To enable comparison between municipalities, both public expenditure on medical consultations and size of retired population were normalized in accordance with the total population size of each municipality. Data on population size in 2013 were therefore also retrieved from Statistics Denmark (StatisticsDenmark, 2019).

\subsubsection{Construction of dataset}

The final dataset is cross-sectional, consisting of 551 observations (unique residential buildings) in relation to the storm surge of 5 December 2013, with a geographical coverage of 29 Danish municipalities. In the study, observations of residential buildings that are listed as an apartment on the first floor and above, as well as observations of no building insurance being claimed but only inventory insurance from the storm surge being collected, were omitted.

\subsection{Econometric specification}

\subsubsection{Multiple regression analysis}

Within economics, multiple regression analysis using Ordinary Least Squares (OLS) is a widely used econometric method of constructing multi-variable models from empirical data (Wooldridge, 2013). The method has been applied in a few studies on the determinants of damage costs for flooding events on building (Ootegem et al., 2015), but in some cases the analyses lack sufficient data for the method to be firmly established (Komolafe et al., 2019; Romali et al., 2019). This indicates a need for 
additional studies using econometric methods to estimate the damage from flooding events. The general model is expressed as Equation 1.

Damagecost $=\beta_{0}+\beta_{1} X_{1}+\beta_{2} X_{2}+\ldots+\beta_{k} X_{k}+\epsilon$

where each of the slope coefficients is a partial derivative of $y$ with respect to the $x$ variable it multiplies. That is, holding all other $x$ 's fixed, $\beta_{1}=\partial \mathrm{y} / \partial \mathrm{x}_{1}$ (Wooldridge, 2013). Efficient and non-biased estimates for all parameters can be obtained as long as the basic OLS assumptions are respected. Ensuring linearity in the relationship between the dependent and the independent variables, the model can be estimated as a log-log or log-linear model in order to assess the relative impact of variance in the independent variables on the dependent variables.

\subsubsection{Variable selection and functional form}

For each observation, the original dataset included more than eighty variables, with detailed variables for building characteristics, location, storm characteristics, previous storms, insurance claims and the level of emergency services provided. The literature review provided input into the initial selection of variables, identifying those that several studies have found to be significant predictors of the economic damage from a flooding event (Merz et al., 2013; Zhai et al., 2005; Elmer et al., 2010). In this paper, we apply a two-stage variable selection and definition of functional form in our econometric models. In the first step, we used the R software package 'PanJen' (Jensen and Panduro, 2018) to identify the functional form for each potential explanatory variable. A visual investigation of the relationship between the explanatory variables and the dependent variables indicated that most or some of the relationships cannot be characterized as linear. As a result, we applied the semi-parametric tools in PanJen to compare the performance of different functional forms of the explanatory variables.

To detect the additional predictive power of different types of data, the regression analysis was performed by systematically adding explanatory variables and assessing the resulting statistic, yielding a total of three different models. An overview of the variables included in the final regression models is given in Table B1, while an overview of our a priori variable hypotheses can be found in Table E1, both found in the Appendix. The initial model (Model 1) was estimated based on flooding depth alone. For Model 2, fourteen variables of housing characteristics were added (size, age, heating source, construction materials and distance from bodies of water). Model 3 also included eight variables reflecting the spatial variation in damage costs by including the return period of the storm surge, previous storm surge experience and emergency services in the municipality, in 
addition to variables indicating social vulnerability at the municipal level (retired persons, income and public expenditure on medical consultations). The regression equation for Model 3 is given in Equation 2.

$$
\begin{aligned}
\text { Damage }_{i}=\beta_{0} & +\beta_{1} \ln \left(\text { depth }_{i}\right)+ \\
& +\beta_{2} \ln \left(\text { size }_{i}\right)+\beta_{3} \text { age }_{i}+\beta_{4} \text { renovated }_{i} \\
& +\beta_{5} \text { centralheating }_{i}+\beta_{6} \text { stoveheating }_{i}+\beta_{7} \text { electricheating }_{i}+\beta_{8} \text { heatpumpheating }_{i} \\
& +\beta_{9} \text { lightweightconcret }_{i}+\beta_{10} \text { timbered }_{i}+\beta_{11} \text { brick }_{i}+\beta_{12} \text { concret }_{i} \\
& +\beta_{13} \ln \left(\text { coastdist }_{i}\right)+\beta_{14} \ln \left(\text { lakedist }_{i}\right)+\beta_{15} \ln \left(\text { habourdist }_{i}\right)+ \\
& +\beta_{16} \ln \left(\text { RP }_{i}\right)+\beta_{17} \text { prevcount }_{i}+\beta_{18} \text { EMAS_duration }_{i}+ \\
& +\beta_{19} \ln \left(\text { depth }_{i} * \text { EMAs_duration }_{i}+\beta_{20} \ln (\text { rp })_{i} * \text { EMAS_duration }_{i}\right. \\
& +\beta_{21} \text { retired }_{i}+\beta_{22} \text { income }_{i}+\beta_{23} \text { med_exp }_{i}+\epsilon_{i}
\end{aligned}
$$

\section{Results and discussion}

\section{OLS regression results}

All regression models were estimated using Stata 13 (StataCorp, 2013) ], and the results are presented in Table 2. All mentions of statistical significance in what follows refer to a 5\% significance level, although Table 2 also reports significance levels of $1 \%$ and $10 \%$. The initial and simple model (Model 1), based on inundation depth alone, was included in the study to depict a baseline model in order to identify the change in predictive power when more explanatory variables are added, as in Models 2 and 3. Across all three models, our results indicate that an increase in water depth significantly increases damage costs, which confirms both intuition and previous findings in the literature (Messner, 2007).Furthermore, our results also indicate that individual building characteristics influence damage costs: for example, larger buildings have significantly greater damage (Model 3), and buildings heated by electric and central heating have significantly larger damage costs (Models 2 and 3). In addition, adding spatial variables, such as municipal characteristics, increases explanatory value (higher adjusted R2) without changing the significance levels of most of the variables. Model 3, which captures most of the spatial effects, shows especially the importance of including municipality characteristics, including social vulnerability, resources, the emergency response, etc.

Our preferred model, Model 3, is an extended model including both building characteristics and variables in order to capture specific spatial variations. We include a continuous measure for the return period of the storm surge, $r p$, and a variable, prevcount, that measures historical exposure to storm surges at the municipal level, as captured by the number of historical insurance claims. In addition, we include variables related to the national Emergency Management Agency's Services (EMAS) during the storm surge, which controls for the duration of the effort (EMAS_duration). This variable is linked to the inundation depth and return period, since it is expected that the emergency services have greater representation in areas with higher inundation depths. Furthermore, three spatial variables regarding the socioeconomic characteristics of the municipalities were 
https://doi.org/10.5194/nhess-2020-30

Preprint. Discussion started: 16 March 2020

(c) Author(s) 2020. CC BY 4.0 License.

(c) (1)

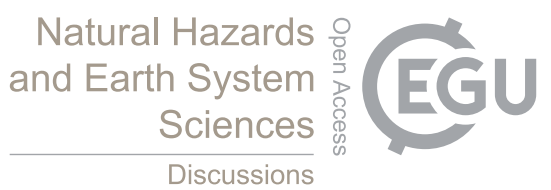

Table 2. OLS regression results

\begin{tabular}{|c|c|c|c|}
\hline & Model 1 & Model 2 & Model 3 \\
\hline $\ln ($ depth$)$ & $\begin{array}{c}0.572^{* * *} \\
(0.046)\end{array}$ & $\begin{array}{c}0.474^{* * *} \\
(0.044)\end{array}$ & $\begin{array}{c}0.375^{* *} \\
(0.079)\end{array}$ \\
\hline $\ln ($ size $)$ & & $\begin{array}{c}0.263 \\
(0.163)\end{array}$ & $\begin{array}{c}0.464^{* * *} \\
(0.169)\end{array}$ \\
\hline age & & $\begin{array}{c}-0.007^{* * *} \\
(0.002)\end{array}$ & $\begin{array}{c}-0.004^{* *} \\
(0.002)\end{array}$ \\
\hline central_heating & & $\begin{array}{c}0.342^{* *} \\
(0.168)\end{array}$ & $\begin{array}{c}0.273^{* *} \\
(0.165)\end{array}$ \\
\hline stove_heating & & $\begin{array}{c}0.416 \\
(0.372)\end{array}$ & $\begin{array}{c}0.496 \\
(0.461)\end{array}$ \\
\hline electric_heating & & $\begin{array}{c}0.730^{* * *} \\
(0.211)\end{array}$ & $\begin{array}{c}0.559^{* * *} \\
(0.192)\end{array}$ \\
\hline heatpump_heating & & $\begin{array}{c}0.545^{* *} \\
(0.224)\end{array}$ & $\begin{array}{c}0.332 \\
(0.211)\end{array}$ \\
\hline $\ln (\mathrm{rp})$ & & & $\begin{array}{c}0.121 \\
(0.079)\end{array}$ \\
\hline PrevCount & & & $\begin{array}{c}0.001 \\
(0.001)\end{array}$ \\
\hline EMAS_duration & & & $\begin{array}{c}-0.013^{* *} \\
(0.005)\end{array}$ \\
\hline $\ln ($ depth)*EMAS_duration & & & $\begin{array}{c}0.000 \\
(0.000)\end{array}$ \\
\hline $\ln (\mathrm{rp}) *$ EMAS_duration & & & $\begin{array}{c}0.002^{* *} \\
(0.001)\end{array}$ \\
\hline Share retired persons & & & $\begin{array}{c}2.681 \\
(2.481)\end{array}$ \\
\hline income per capita & & & $\begin{array}{l}-0.000 \\
(0.000)\end{array}$ \\
\hline medical expenses & & & $\begin{array}{c}-0.001^{* * *} \\
(0.001)\end{array}$ \\
\hline Constant & $\begin{array}{c}10.593^{* * *} \\
(0.165) \\
\end{array}$ & $\begin{array}{c}9.571^{* * *} \\
(0.920) \\
\end{array}$ & $\begin{array}{c}11.865^{* * *} \\
(1.412) \\
\end{array}$ \\
\hline Construction variables & & yes & yes \\
\hline Distance to water bodies & & yes & yes \\
\hline Observations & 551 & 551 & 551 \\
\hline Adjusted $R^{2}$ & 0.211 & 0.321 & 0.367 \\
\hline
\end{tabular}

Robust standard errors in parentheses

$* p<0.10, * * p<0.05, * * * p<0.01$

EMAS $=$ Emergency Management Agency Services

220 added. As described earlier, these variables are included to capture any difference in damage costs at the spatial level of the municipality with regard to how vulnerable local communities are. The hypothesis is that the vulnerability of a local community could influence the municipality's overall efforts to reduce the expected damage costs so that municipalities that are more vulnerable have less economic and social capital with which to respond to extreme events such as storm surges. The overall explanatory power of the model as captured by the adjusted R2 is 0.37 . The increase in the explanatory power from 
0.21 in Model 1 and 0.32 in Model 2 reflects the finding of Ootegem et al. (2015), who also saw an improvement by including variables for socio-economic status and building characteristics.

Model 3 shows a statistically significant increase in the resulting damage of $0.38 \%$ per $1 \%$ increase in inundation depth, a positive relationship also identified previously in the literature (Jonkman et al., 2008). The effect on damage from the inundation depth is smaller compared to Models 1 and 2, indicating the presence of omitted variable bias in those models.

We find that several of the building characteristics, such as size, age and heating source, significantly impact on the size of the damage costs. Larger buildings have statistically significant greater damage, with a $1 \%$ increase in the size of the building leading to an increase of $0.46 \%$. The finding of a positive relationship between size and damage cost is confirmed by a study by Carisi et al. (2018), who also find a significant, positive relationship.Older buildings are subject to lower expected damage costs, with a ten-year increase in a building's age reducing damage by $4 \%$. Interpreting the causal effects of age upon damage costs is not straightforward. It is likely that the observed negative effects of age on damage costs could be due to older buildings having been built in safer locations, for example, in areas not prone to flooding. There has been an increasing tendency in Denmark, as well as globally, for the development of new settlements and neighborhoods to be located closer to flood-prone areas (Seto et al., 2011; Small and Nicholls, 2003), presumably motivated by the amenity benefits gained from proximity to the water. This trend could explain why older residential buildings are expected to have lower damage costs than newer buildings.

Furthermore, our results show that, compared to buildings heated by district heating, those heated by an electrical heating system suffer more damage, with a figure of $63.15 \%$ as opposed to $47.67 \%{ }^{4}$.Of the 551 observations in our data, 241 buildings have central heating, 139 have electric heating, 64 buildings are heated by a heat pump and five have stove heating (see Table ?? in the Appendix). The reference category, district heating, is only observed for 102 buildings. Nevertheless this category was chosen as a reference since the four remaining categories are all characterized by being building-specific and thus are potentially more susceptible to damage than a district heating system would be. So, although these percentage effects seems large compared to the other effects we found, they essentially capture the greater sensitivity of a localized heating system compared to a network-based system and highlight the sensitivity of these systems to a storm-surge event. The interpretation of the heating systems' impact on damage costs could reflect the locations of different heating systems within buildings and thus the costs of repairing damaged heating systems. Confirming this hypothesis, heat pumps and electric heaters, which we find contribute most to damage costs, are often placed in low-to-ground positions within buildings.

The direction and significance of both the age of a building and whether it has electrical and central heating remains unchanged between Models 2 and 3, suggesting that the relevance of these variables is robust to the inclusion of the specified spatial variables. However, the size of the effect is reduced, and the heat pump does not seem to suffer greater damage than the district heating systems in Model 3. Nonetheless the effect of size is only significant in Model 3, which indicates that including important spatial variables reduces an omitted variable bias. We find no indication in any of the models that exterior construction materials influence damage costs, nor distance from the nearest coast or lake. Also, the results indicate that the storm intensity $(r p)$ and the number and severity of prior storm surges have no significant effect on the damage costs.

\footnotetext{
${ }^{4}$ For the dummy variables capturing heating source, their effect must be specifically calculated and cannot be directly read from Table 2 . The formula we used for calculating the effect of dummy variables is: $100^{*}\left(\exp \left(\beta_{x}-0.5 \beta_{\text {sderror }}^{2}\right)-1\right)($ Kennedyet al., 1981)
} 
Interestingly, the variables regarding emergency responses show a significant decrease in damage costs the more time is spent on emergency actions. There is a larger decrease in damage costs at lower inundation depths, as captured by the partial effect of the interaction term $\left(E M A S \_d u r a t i o n+\ln (\text { depth })^{*} E M A S \_d u r a t i o n\right)$. The calculated reduction in damage per extra hour spent on emergency management ranges from $1.16 \%$ for the lowest recorded inundation depth to a reduction in damage of $0.16 \%$ for the highest recorded inundation depth.

We find no effect of either the share of retired persons in a municipality or the average income per capita on damage costs. However, the results indicate that municipalities with greater public expenditure on medical consultations also have statistically lower damage costs. Intuitively, we would have assumed that municipalities with higher public expenditure on medical consultations indicate a vulnerable community, which would suggest that the effect on damage costs should be positive. On the other hand, this could also be seen as an indication of a resourceful community in which people act on their health problems, which could explain the negative relationship we observe.

To sum up, our results indicate a substantial increase in explanatory power from $21 \%$ to $39 \%$, going from a simple linear regression including only inundation depth (Model 1) to a multivariable regression model (Model 3). Furthermore, our study shows that adding explanatory variables besides inundation depth decreases the effect of inundation depth alone, for example, a fall from a $0.57 \%$ increase in damage costs to $0.37 \%$ from a $1 \%$ increase in inundation depth - a substantial difference. Thus, our study indicates that using only the simulated inundation depth to predict damage costs could lead to these costs being over-estimated. Specifically, the inclusion of spatial variables changes the effect size of several of the explanatory variables, adding to the explanatory power of our model.

If OLS regressions are to provide unbiased and consistent estimates, we have to assume that observations are independent of one another (Lesage, 2014). In this case, we might suspect the presence of neighborhood effects that influence damage costs at a lower level than the municipal level. As pointed out by Anselin and Arribas-Bel (2013), it is only in very restricted cases that fixed spatial effects, such as those we include in Model 3, correctly account for the possible spatial dependence between observations. An example of such a small-scale spatial effect could be the degree of social cohesion among neighbors, which potentially could influence their ability or willingness to help each other during an extreme event such as a storm surge. Not controlling for such a potential effect in the model set up means that spatial auto-correlation might be present, leading to biased and inconsistent OLS estimators. To investigate whether Models 2 or 3 display any spatial auto-correlation, we compare model performance based on Moran's I (see Table F1 in Appendix), indicating that spatial autocorrelation is present in Model 2 (Moran's I= $0.117 * * *$ ). However, in Model 3, which includes spatial variables at the municipality level, we find that the evidence of significant spatial autocorrelation has decreased (Moran's I $=0.062 * *$ ). In particular, the test for spatial autocorrelation in the error term is only significant at a $10 \%$ level, suggesting that the model accounts for most of the unobserved spatial effects. This again highlights the importance of including variables representing spatial variance and not just focusing on specific house or individual characteristics. The indication that some spatial dependence is still present in the extended model suggests that future studies could explore this further using, for example, spatial econometric methods (LeSage and Pace, 2009; Cliff, 1973). 


\section{Conclusion}

Multivariable damage cost models of storm-surge flooding are essential in supporting cost-effective investments in adaptation options. First, they can highlight individual or combinations of variables that are driving high economic losses, showing which variables are particularly important to address in devising risk-reduction strategies. Secondly, the models can be used to prioritize actions between different geographical areas and provide an estimate of how much society should be willing to invest in adaptive measures. Our results confirm that multivariable models can provide more accurate results than a simple model. Through the inclusion of a wide set of explanatory variables in the damage costs of coastal flooding, our study particularly highlights the necessity of controlling for spatial variation in estimating damage costs, whether in relation to socio-economic conditions, flooding characteristics or emergency services. Including more variables increases the explanatory power of our model from $21 \%$ in the simple model, where inundation depth is the only variable, to $39 \%$ in the multivariable model. Several different variables are found to significantly influence damage costs. Besides inundation depth, they include building characteristics (size, age), emergency response efforts and type of heating source. In particular, the presence of electric heating systems appears to be surprisingly sensitive to flooding, as damage costs are found to be much higher for buildings with such systems compared with, for example, houses drawing on district heating. The chief benefit of our approach is the stringent econometric method we have used. In theory, this approach should facilitate transferability to other settings similar to those in our study. We are aware that the type of data used for this model is not widely accessible in all regions and countries, which is why the results of Model 3 will not easily be transferred to other regions. However, our study still highlights the importance of including variables that can account for differences across municipalities and regions. The results of our study should thus be replicated in other settings before being used as input to adaptation option strategies. 
https://doi.org/10.5194/nhess-2020-30

Preprint. Discussion started: 16 March 2020

(c) Author(s) 2020. CC BY 4.0 License.

Table A1. DSC Insurance data for the storm surge of 5'th December 2013

\begin{tabular}{|c|c|c|c|c|c|c|c|}
\hline & \multicolumn{2}{|l|}{ Residential } & \multicolumn{2}{|l|}{ Leisure } & \multicolumn{2}{|l|}{ Business } & \multirow[t]{2}{*}{ Total } \\
\hline & & Share & & Share & & Share & \\
\hline Insurance claims (\#) & 1294 & $47 \%$ & 1098 & $40 \%$ & 369 & $13 \%$ & 2.761 \\
\hline Insurance payouts (\#) & 927 & $43 \%$ & 942 & $44 \%$ & 267 & $13 \%$ & 2.136 \\
\hline Payouts ()$€$ & $61,195,309$ & $47 \%$ & $50,301,761$ & $39 \%$ & $17,726,855$ & $14 \%$ & 129.223 .925 \\
\hline & Payout, $€$ & Share & & & & & \\
\hline Building & $106,778,147$ & $83 \%$ & & & & & \\
\hline Chattel & $12,534,970$ & $10 \%$ & & & & & \\
\hline Rehousing & $2,434,311$ & $2 \%$ & & & & & \\
\hline Own risk & $7,476,496$ & $6 \%$ & & & & & \\
\hline Total & $129,223,925$ & & & & & & \\
\hline
\end{tabular}


https://doi.org/10.5194/nhess-2020-30

Preprint. Discussion started: 16 March 2020

(c) Author(s) 2020. CC BY 4.0 License.

Table B1. Variables included in final regression models

\begin{tabular}{|c|c|c|c|}
\hline Variable & Model 1 & Model 2 & Model 3 \\
\hline \multicolumn{4}{|l|}{ Building damage } \\
\hline Damage cost & $\mathrm{X}$ & $\mathrm{X}$ & $\mathrm{X}$ \\
\hline \multicolumn{4}{|l|}{ Storm surge characteristics } \\
\hline Inundation depth & $\mathrm{X}$ & $\mathrm{X}$ & $\mathrm{X}$ \\
\hline Return Period & & & $\mathrm{X}$ \\
\hline \multicolumn{4}{|l|}{ Building characteristics } \\
\hline Size & & $\mathrm{X}$ & $\mathrm{X}$ \\
\hline Age & & $\mathrm{X}$ & $\mathrm{X}$ \\
\hline Heating source (dummy: central, stove, electric, heat pump, district) & & $\mathrm{X}$ & $\mathrm{X}$ \\
\hline Outer construction (dummy: wood, timbered, concrete, lightweigt concrete, bricks) & & $\mathrm{X}$ & $\mathrm{X}$ \\
\hline Renovations (dummy: yes, no) & & $\mathrm{X}$ & $\mathrm{X}$ \\
\hline Distance to lake & & $\mathrm{X}$ & $\mathrm{X}$ \\
\hline Distance to coast & & $\mathrm{X}$ & $\mathrm{X}$ \\
\hline Distance to habour & & $\mathrm{X}$ & $\mathrm{X}$ \\
\hline \multicolumn{4}{|l|}{ Flood experience } \\
\hline Number of previous storms & & & $\mathrm{X}$ \\
\hline \multicolumn{4}{|l|}{ Emergency Management Agency Services, EMAS } \\
\hline EMAS duration (hours spent) & & & $\mathrm{X}$ \\
\hline \multicolumn{4}{|l|}{ Social vulnerability indicators } \\
\hline Population share of retired persons & & & $\mathrm{X}$ \\
\hline Income per capita & & & $\mathrm{X}$ \\
\hline public expenditures on medical consultations & & & $\mathrm{X}$ \\
\hline
\end{tabular}

Reference categories for dummy variables in subsequent econometric models are: Heating source $=$ district heating and Outer construction $=$ wood 
https://doi.org/10.5194/nhess-2020-30

Preprint. Discussion started: 16 March 2020

(c) Author(s) 2020. CC BY 4.0 License.

Table C1. Descriptive statistics for continous variables

\begin{tabular}{lcccc}
\hline \hline & mean & sd & $\min$ & $\max$ \\
\hline damage costs (y) & 501441.02 & 564825.10 & 1455.00 & 3728359.25 \\
depth & 44.58 & 53.01 & 1.00 & 296.00 \\
rp & 687.21 & 393.57 & 7.00 & 1000.00 \\
size & 145.61 & 52.80 & 45.00 & 364.00 \\
age & 61.05 & 44.95 & 0.00 & 239.00 \\
ln(coast_dist) & 4.66 & 1.18 & 1.24 & 7.94 \\
ln(lake_dist) & 5.96 & 0.77 & 3.12 & 7.36 \\
PrevCount & 39.19 & 91.14 & 0.00 & 602.00 \\
PrevCostIndex & 4.29 & 12.95 & 0.00 & 100.00 \\
EMAS_duration & 262.72 & 213.25 & 0.00 & 582.40 \\
EMAS_count & 19.98 & 14.71 & 0.00 & 38.00 \\
ln(depth)*EMAS_count & 71.57 & 59.40 & 0.00 & 173.84 \\
ln(rp)*EMAS_count & 133.95 & 105.52 & 0.00 & 262.49 \\
ln(depth)*EMAS_duration & 955.98 & 888.76 & 0.00 & 3314.08 \\
ln(rp)*EMAS_duration & 1770.74 & 1512.74 & 0.00 & 4023.10 \\
retired persons & 0.23 & 0.04 & 0.19 & 0.35 \\
income per capita & 376151.35 & 63298.34 & 280394.00 & 599126.00 \\
medical expenses & 2550.63 & 173.29 & 2194.22 & 3031.16 \\
\hline \hline
\end{tabular}


https://doi.org/10.5194/nhess-2020-30

Preprint. Discussion started: 16 March 2020

(c) Author(s) 2020. CC BY 4.0 License.

Table D1. Descriptive statistics for dummy variables

\begin{tabular}{lc}
\hline \hline Construction variables & Observations \\
\hline renovated & 202 \\
\hline lightweight_concrete & 33 \\
timbered & 17 \\
brick & 362 \\
wood (reference) & 131 \\
\hline central_heating & 241 \\
stove_heating & 5 \\
electric_heating & 139 \\
heatpump_heating & 64 \\
district_heating (reference) & 102 \\
\hline \hline
\end{tabular}


Table E1. Variable specific hypotheses.

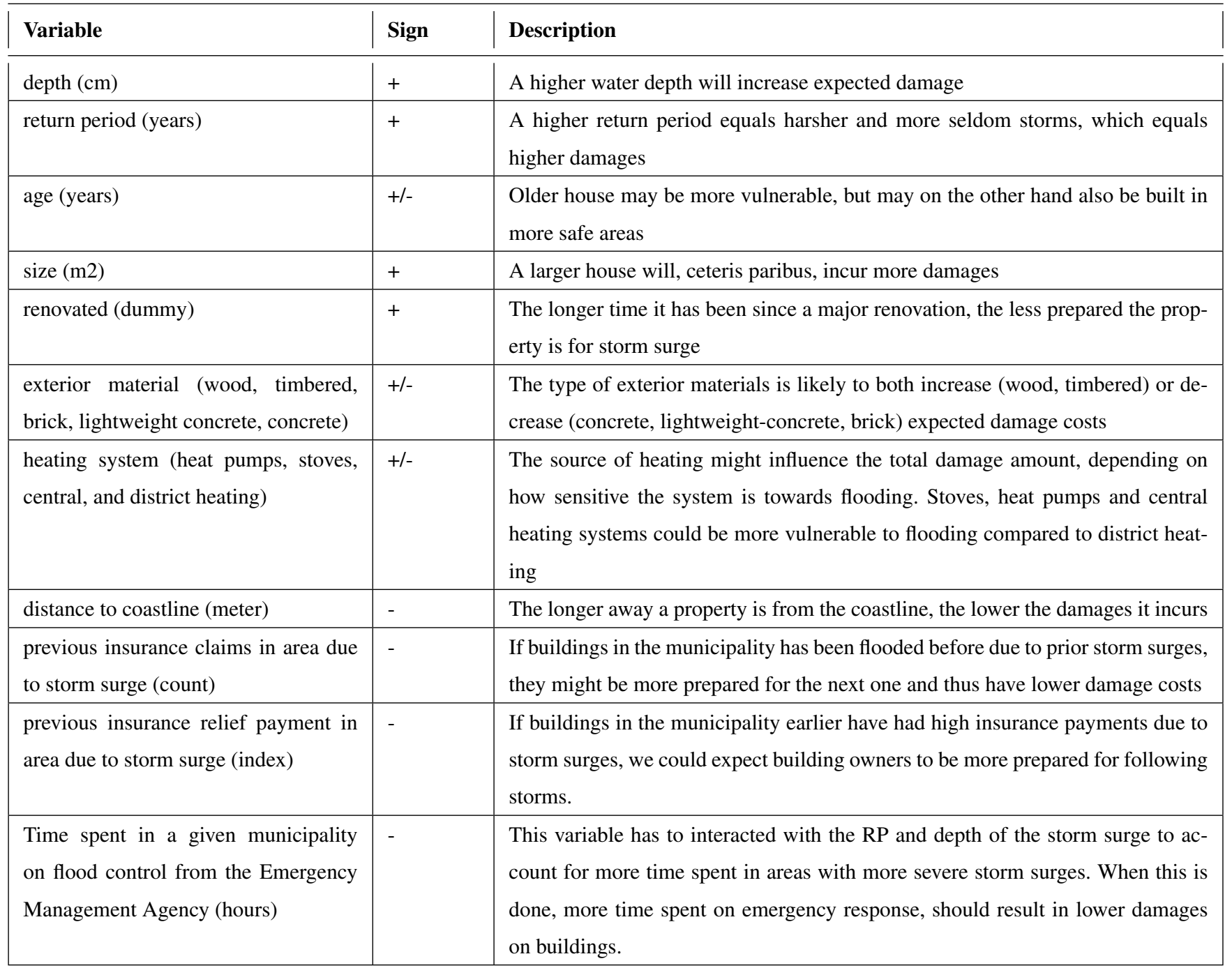


https://doi.org/10.5194/nhess-2020-30

Preprint. Discussion started: 16 March 2020

(c) Author(s) 2020. CC BY 4.0 License.

Table F1. Test of global spatial autocorrelation in OLS residuals

\begin{tabular}{lll}
\hline Model & Moran's I & Robust LM-test for spatial error \\
\hline Model 2 & $0.117^{* * *}$ & $10.42^{* * *}$ \\
\hline Model 3 & $0.062^{* *}$ & $2.86^{*}$ \\
\hline \hline & \multicolumn{1}{l}{$p<0.10,{ }^{* *} p<0.05,{ }^{* * *} p<0.01$}
\end{tabular}


https://doi.org/10.5194/nhess-2020-30

Preprint. Discussion started: 16 March 2020

(C) Author(s) 2020. CC BY 4.0 License.

(c) (1)

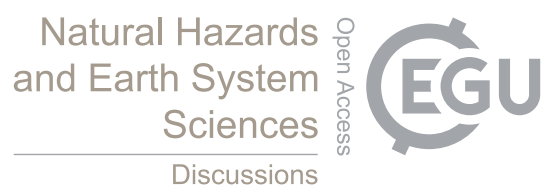

Author contributions. L.S.S., L.B. and M.L.D. designed the analysis, L.S.S. and L.B ran the analysis. All authors contributed to the draft of the paper.

Competing interests. No competing interests are present

Acknowledgements. The authors would like to thank the DSC and EMAS for kindly making their data available and sharing it for the analysis.

315 We would also like to acknowledge the support of the Innovation Fund Denmark, funding the COHERENT research project (7048-00004B). 


\section{References}

Amadio, M., Scorzini, A. R., Carisi, F., Essenfelder, A. H., Domeneghetti, A., Mysiak, J., and Castellarin, A.: Testing empirical and synthetic flood damage models: the case of Italy, Natural Hazards and Earth System Sciences, 19, 661-678, 2019.

André, C., Monfort, D., Bouzit, M., and Vinchon, C.: Contribution of insurance data to cost assessment of coastal flood damage to residential buildings: insights gained from Johanna (2008) and Xynthia (2010) storm events, Natural Hazards and Earth System Sciences, 13, 20032012, 2013.

Anselin, L. and Arribas-Bel, D.: Spatial fixed effects and spatial dependence in a single cross-section, Papers in Regional Science, 92, 3-17, 2013.

BBR: The Danish Building and Housing Register, https://bbr.dk/forside, 2019.

Cammerer, H., Thieken, A. H., and Lammel, J.: Adaptability and transferability of flood loss functions in residential areas, Natural Hazards and Earth System Sciences, 13, 3063-3081, 2013.

Carisi, F., Schröter, K., Domeneghetti, A., Kreibich, H., and Castellarin, A.: Development and assessment of uni- and multivariable flood loss models for Emilia-Romagna (Italy), Natural Hazards and Earth System Sciences, 18, 2057-2079, https://doi.org/10.5194/nhess-182057-2018, https://www.nat-hazards-earth-syst-sci.net/18/2057/2018/, 2018.

Cliff, A. D.: Spatial autocorrelation, Tech. rep., 1973.

DCA: Danish Coastal Authority, Højvandsstatistikker 2017, Tech. rep., Ministry of Environment and Food, Denmark, 2018.

DEMA: Danish Emergency Management Agency, https://brs.dk/eng/Pages/dema.aspx, 2019.

DSC: Danish Storm Council, https://www.danishstormcouncil.dk/, 2019.

Elmer, F., Thieken, A. H., Pech, I., and Kreibich, H.: Influence of flood frequency on residential building losses, Natural Hazards and Earth System Sciences, 10, 2145-2159, 2010.

Figueiredo, R., Schröter, K., Weiss-Motz, A., Martina, M. L., and Kreibich, H.: Improving accuracy and quantifying uncertainty in flood loss estimations through the use of multi-model ensembles, Nat. Hazards Earth Syst. Sci. Discuss., pp. 1-34, 2017.

Figueiredo, R., Schröter, K., Weiss-Motz, A., Martina, M. L., and Kreibich, H.: Multi-model ensembles for assessment of flood losses and associated uncertainty, Natural Hazards and Earth System Sciences, 18, 1297, 2018.

Grahn, T. and Nyberg, R.: Damage assessment of lake floods: Insured damage to private property during two lake floods in Sweden 2000/2001, International Journal of Disaster Risk Reduction, 10, 305 - 314, https://doi.org/https://doi.org/10.1016/j.ijdrr.2014.10.003, http://www.sciencedirect.com/science/article/pii/S2212420914000892, 2014.

Jensen, C. U. and Panduro, T. E.: PanJen: an R package for ranking transformations in a linear regression, R Journal, 10, 109-121, 2018.

Jongman, B., Kreibich, H., Apel, H., Barredo, J. I., Bates, P. D., Feyen, L., Gericke, A., Neal, J., Aerts, J. C. J. H., and Ward, P. J.: Comparative flood damage model assessment: towards a European approach, Natural Hazards and Earth System Sciences, 12, 3733-3752, https://doi.org/10.5194/nhess-12-3733-2012, https://www.nat-hazards-earth-syst-sci.net/12/3733/2012/, 2012.

Jonkman, S. N., Bočkarjova, M., Kok, M., and Bernardini, P.: Integrated hydrodynamic and economic modelling of flood damage in the Netherlands, Ecological economics, 66, 77-90, 2008.

Kelejian, H. H. and Prucha, I. R.: Specification and estimation of spatial autoregressive models with autoregressive and heteroskedastic disturbances, Journal of econometrics, 157, 53-67, 2010.

Kennedy, P. E. et al.: Estimation with correctly interpreted dummy variables in semilogarithmic equations [the interpretation of dummy variables in semilogarithmic equations], American Economic Review, 71, 801-801, 1981. 
https://doi.org/10.5194/nhess-2020-30

Preprint. Discussion started: 16 March 2020

(c) Author(s) 2020. CC BY 4.0 License.

(c) (i)

Komolafe, A., Herath, S., and Avtar, R.: Establishment of detailed loss functions for the urban flood risk assessment in Chao Phraya River basin, Thailand, Geomatics, Natural Hazards and Risk, 10, 633-650, https://doi.org/10.1080/19475705.2018.1539038, 2019.

LeSage, J. and Pace, R. K.: Introduction to spatial econometrics, Chapman and Hall/CRC, 2009.

Lesage, J. P.: What Regional Scientists Need to Know About Spatial Econometrics, SSRN Electronic Journal, 44, https://doi.org/10.2139/ssrn.2420725, 2014.

Merz, B., Kreibich, H., Thieken, A., and Schmidtke, R.: Estimation uncertainty of direct monetary flood damage to buildings, Natural Hazards and Earth System Science, 4, 153-163, 2004.

Merz, B., Kreibich, H., Schwarze, R., and Thieken, A.: Review article" Assessment of economic flood damage", Natural Hazards and Earth System Sciences, 10, 1697-1724, 2010.

Merz, B., Kreibich, H., and Lall, U.: Multi-variate flood damage assessment: a tree-based data-mining approach, Natural Hazards and Earth System Sciences, 13, 53-64, 2013.

Merz, B., Aerts, J., Arnbjerg-Nielsen, K., Baldi, M., Becker, A., Bichet, A., Blöschl, G., Bouwer, L. M., Brauer, A., Cioffi, F., Delgado, J. M., Gocht, M., Guzzetti, F., Harrigan, S., Hirschboeck, K., Kilsby, C., Kron, W., Kwon, H.-H., Lall, U., Merz, R., Nissen, K., Salvatti, P., Swierczynski, T., Ulbrich, U., Viglione, A., Ward, P. J., Weiler, M., Wilhelm, B., and Nied, M.: Floods and climate: emerging perspectives for flood risk assessment and management, Natural Hazards and Earth System Sciences, 14, 1921-1942, https://doi.org/10.5194/nhess14-1921-2014, https://www.nat-hazards-earth-syst-sci.net/14/1921/2014/, 2014.

Messner, F.: Evaluating flood damages: guidance and recommendations on principles and methods, T09-06-01, 2007.

Middelmann-Fernandes, M.: Flood damage estimation beyond stage-damage functions: an Australian example, Journal of Flood Risk Management, 3, 88-96, https://doi.org/10.1111/j.1753-318X.2009.01058.x, https://onlinelibrary.wiley.com/doi/abs/10.1111/j.1753-318X. 2009.01058.x, 2010.

Moel, H., Asselman, N., and Aerts, J.: Uncertainty and sensitivity analysis of coastal flood damage estimates in the west of the Netherlands, pp. 1045-1058, 2012.

Ootegem, L., Verhofstadt, E., Van Herck, K., and Creten, T.: Multivariate pluvial flood damage models, Environmental Impact Assessment Review, 54, https://doi.org/10.1016/j.eiar.2015.05.005, 2015.

Pistrika, A., Tsakiris, G., and Nalbantis, I.: Flood depth-damage functions for built environment, Environmental Processes, 1, 553-572, 2014.

Prahl, B. F., Boettle, M., Costa, L., Kropp, J. P., and Rybski, D.: Damage and protection cost curves for coastal floods within the 600 largest European cities, Scientific Data, 5, https://doi.org/10.1038/sdata.2018.34, 2018.

Prettenthaler, F., Amrusch, P., and Habsburg-Lothringen, C.: Estimation of an absolute flood damage curve based on an Austrian case study under a dam breach scenario, Natural Hazards and Earth System Sciences, 10, 881-894, 2010.

Romali, N., Yusop, Z., Zaki, N., Sulaiman, M., Ahmad Abdul Ghani, N. A., and Sulaiman, S.: Flood Damage Function Model for Residential area in Kuantan: A Preliminary Study, International Journal of Integrated Engineering, 11, https://doi.org/10.30880/ijie.2019.11.02.022, 2019.

Schröter, K., Kreibich, H., Vogel, K., Riggelsen, C., Scherbaum, F., and Merz, B.: How useful are complex flood damage models?, Water Resources Research, 50, 3378-3395, https://doi.org/10.1002/2013WR014396, 2014.

Seto, K. C., Fragkias, M., Güneralp, B., and Reilly, M. K.: A Meta-Analysis of Global Urban Land Expansion, PLOS ONE, 6, 1-9, https://doi.org/10.1371/journal.pone.0023777, https://doi.org/10.1371/journal.pone.0023777, 2011.

Small, C. and Nicholls, R.: A Global Analysis of Human Settlement in Coastal Zones, Journal of Coastal Research, 19, https://doi.org/10.2307/4299200, 2003. 
https://doi.org/10.5194/nhess-2020-30

Preprint. Discussion started: 16 March 2020

(c) Author(s) 2020. CC BY 4.0 License.

(c) (1)

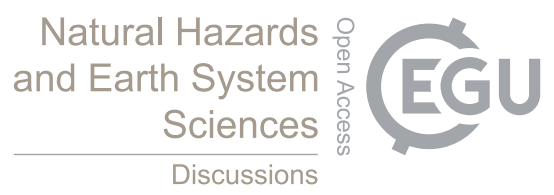

Smith, D.: Flood damage estimation - A review of urban stage-damage curves and loss functions, Water SA, 20, 231-238, 1994.

Spekkers, M., Kok, M., Clemens, F., and Ten Veldhuis, J.: Decision-tree analysis of factors influencing rainfall-related building structure and content damage, Natural Hazards and Earth System Sciences, 14, 2531-2547, 2014.

StataCorp, L.: Stata: release 13-statistical software, TX: College Station, 2013.

StatisticsDenmark: Data retrieved from StatBank Denmark, data set: INDKF111, SYGU1, RAS209, and BY2 https://www.statistikbanken. dk/statbank5a/default.asp?w=1920, 2019.

Wooldridge, J. M.: Introductory Econometrics: A Modern Approach, Fifth Edition, South-Western, Cengage Learning, 2013.

Zhai, G., Fukuzono, T., and Ikeda, S.: MODELING FLOOD DAMAGE: CASE OF TOKAI FLOOD 2000 1, JAWRA Journal of the American Water Resources Association, 41, 77-92, 2005.

400 Zhou, Q., Panduro, T. E., Thorsen, B. J., and Arnbjerg-Nielsen, K.: Verification of flood damage modelling using insurance data, Water Science and Technology, 68, 425-432, 2013. 